Eugene C. Nelson, DSc

Celia O. Larson, PhD

Allyson R. Davies, $\mathrm{PhD}$

David Gustafson, PhD

Pedro L. Ferreira, PhD

John E. Ware, Jr, PhD

\title{
The Patient Comment Card: A System to Gather Customer Feedback
}

patients to the high-quality, low-cost providers. ${ }^{2}$ Health care organizations must now become experts at determining what patients need and expect. Moreover, they must learn to search continuously for better ways to at least satisfy, and hopefully delight, their customers. ${ }^{3}$ This article describes the development and results from the field testing of the Patient Comment Card (PCC) - a patient questionnaire that hospitals can use, given a sufficiently high response rate, to measure quality from the customer's point of view.

\section{Patient Comment Card}

The PCC is a "third generation" form developed on the basis of extensive earlier work to design, test, and validate a comprehensive system for measuring patients' judgments of hospital quality. Development began four years ago with the pilot test of a 108-item form in ten hospitals. ${ }^{4}$ On the basis of this form a 68-item questionnaire (Hospital Quality Trends: Patient Judgments System [PJS]) was developed in 1987, which 174 hospitals across the United States are using to measure the "voice of the customer," monitor long-term trends in quality, identify high-priority areas for improvement, and benchmark their results against the best achieved..$^{5,6}$ The PJS is an essential element in the efforts of many hospitals to initiate total quality management and organizationwide continuous quality improvement (CQI) activities $;^{7,8}$ the PJS produces values for standardized indicators of quality trends on the basis of a random sample of hospitalized patients.

The system works in this way. First, a random sample of patients is selected from the entire population of hospital patients seen during a three-month period. Second, NCG Research, Inc (Nashville, Tenn), manages sample selection, data collection (using mailed questionnaires), follow-up of nonrespondents, data analysis, and report production. Third, hospitals receive a report displaying trends on quality measures and use the report to plan quality improvement activities and to evaluate level of satisfaction.

By 1988 it was apparent that many of the hospitals using the PJS wanted a complementary patient feedback system. They wanted a measure that would be brief and inexpensive to operate and that would allow all patients to comment on their care and provide rapid, ongoing information on a brief set of quality indicators.

To address these needs, in 1988 a multidisciplinary team was assembled to develop a questionnaire that could offer all patients the opportunity to comment on the hospital care that they received. This feedback would be used to support the hospital's guest relations (for example, responsiveness to customer feedback) and risk management programs. Researchers also wanted to determine the feasibility of using the questionnaire to generate data for developing timely, quantitative measures of quality; if proven reliable and valid, these indicators could be used to provide rapid feedback on trends in overall quality.

\section{Methods}

The PCC was developed in the following three stages:

- A short-form questionnaire was constructed, based on the PJS and its 108-item predecessor;

- Two pilot tests were conducted to evaluate reliability, validity, and response rates; and 
- A field test was performed to measure response bias under normal operating conditions (that is, when hospitals rely on internal collection and analysis of data rather than on an outside professional survey organization).

Questionnaire development and description. The pilot test version of the PCC (see Appendix A) included a total of 40 questions: 14 open-ended items for comments on care and 26 fixed-response questions, the latter including 9 items on specific features of care (for example, x-ray, laboratory), 2 items on behavioral intentions (for example, would recommend, would return), 1 item on overall quality of care, and 5 demographic/descriptive items (for example, where stayed in hospital, room number, year of birth).

The PCC was developed by an interdisciplinary team that included the authors and professional staff from four hospitals, including administrators, researchers, quality coaches, and marketing directors. The starting point for PCC form development was the "parent" questionnaire, ${ }^{*}$ the 68 -item PJS, ${ }^{6}$ which itself was preceded by the 108-item patient judgments of hospital quality (PJHQ) form. ${ }^{4}$ These three instruments contain items to assess patient perceptions of various hospital processes (for example, admissions, daily care, information, nursing services, physician services, ancillary services, living arrangements, discharge, and billing procedures).

The first nine questions of the parent questionnaire - beginning with admissions and ending with dischargewere written to obtain evaluations of features of care that tend to be important to patients (Appendix A). These items (for example, privacy and food) were either taken directly from the PJS

\footnotetext{
"Two "short-form" measures (10 to 20 items each) have been developed: the PCC and the PJS short-form. ${ }^{9}$ The PCC is quite different from the PJS "short form." The former, as the name implies, was designed primarily to obtain comments from patients and overall quantitative indicators whereas the latter was designed to identify the smallest number of items that could be used to estimate the overall "total process" score on the parent questionnaire. (The total process score is a single indicator reflecting the overall quality of a hospital's care and services.)
}

form or were combined from several PJS items (for example, admissions and nurses). Each question starts with a "signpost" (for example, "your nurses") that signals the topic to be rated, followed by a "descriptor" that mentions several distinct characteristics (for example, skill, caring and concern) of that particular area. Each of these nine items was designed to provide a single, overall indicator of a much wider dimension of quality and were combined to form a summary measure of quality called the total process scale.

A block of nine questions at the top of the PCC asks patients to rate specific departments or areas of hospital service (for example, x-ray, laboratory, respiratory/breathing therapy).

Patients rate each question by choosing one of five response categories (excellent, very good, good, fair, or poor). These responses are linearly transformed from a five-point scale to range from 0 to 100 . With this transformation, a score of 100 would indicate excellent, whereas a score of 0 would indicate poor.

Three items (overall quality of care and services, would you recommend this hospital?, and would you return to this hospital?) query overall patient satisfaction with the hospital. Responses can also be used to develop general quality indicators for the purpose of assessing the construct validity of more specific quality characteristics. Five questions (age, sex, location in the hospital, room number, and discharge date) gather demographic and descriptive information that can be used in analysis of results by certain subgroups.

In addition to the fixed-response items, the PCC also includes 14 spaces for write-in responses; most invite comments on specific questions but two are open-ended questions that aim to capture patients' reports of good or bad experiences.

The PCC form itself is professionally printed, multicolored, folds up for easy mailing, and is preaddressed and prestamped to encourage response. It can be modified to show the name of the hospital and its chief operating officer. The excellent-to-poor response range for the fixed-response items referring to features of care was selected for two reasons:

- It is consistent with the PJS and PJHQ forms; and

- Research has demonstrated the superiority of the excellent-to-poor scale over the very satisfied-to-very dissatisfied type. ${ }^{10}$

Evaluation of PCC: Reliability, Validity, Response Rates, and Response Biases The next step was to pilot test the PCC questionnaire. Two separate pilot tests were conducted - one to evaluate reliability and validity and one to determine the effect on response rates of different methods of administering the questionnaire.

Six-hospital pilot test of reliability and validity. The first 40 respondents (a consecutive series of patients who had completed the PJS) from each of six hospitals already using the 68-item PJS were mailed the PCC form. Of the 240 patients, $157(65 \%)$ responded. Data from the completed questionnaires were used to evaluate reliability and validity.

Reliability was assessed at both patient and hospital levels. Two types of reliability were assessed: test retest and internal consistency. Six items of the 68-item PJS form were identical to those on the briefer PCC; comparison of these items at two different points in time provided a measure of testretest reliability. Values for the first nine items, which were used to construct the total process scale, were summed without weighting; the interrelationships among these items were assessed to examine internal-consistency reliability (that is, the degree to which these measures of the process of care correlate with one another in the expected manner). Cronbach's alpha coefficient, a standard reliability coefficient, was used to measure the internal consistency of the multi-item scale, not the reliability of individual items. Hospitallevel reliability was assessed using oneway analysis of variance to estimate the intraclass correlation (that is, Rtt, which is the ratio of between-hospital to within-hospital variation).

The following two approaches were used to evaluate the construct validity of the PCC:

- Multitrait-multimethod (MTMM) 
The Patient Comment

Card: A System to Gather Customer Feedback

analysis, which tests convergent and discriminant validity; and

- Variability of ratings across hospitals (that is, hospitals expected to differ on quality should score differently on the PCC).

Convergent validity (how well a new measure correlates with other methods of measuring the same dimensions of quality) and discriminant validity (the extent to which an item correlates more highly with theoretically related items than with items that are less theoretically related) were evaluated by using the MTMM analysis technique. This approach was used because the PCC and the PJS represent two different methods to measure several different "traits" (that is, food, privacy, quality of care, would return, and would recommend). A microcomputer program, "A Microcomputer Program for Analyzing Multitrait-Multimethod Matrices," was used to perform these evaluations. ${ }^{11}$ The convergent validity criterion, which requires that "the correlation between measures of the same trait using the two different methods should be large and different from zero, ${ }^{10}$ was assessed by computing the average validity correlation (on-diagonal relationships). The discriminant validity criterion requires that the correlation between measures of the same trait measured by different methods (for example, PCC nurses and PJS nurses) be greater than the correlations between different traits measured by the same method (for example, PCC nurses and PCC physicians) or than the correlation between different traits measured by different methods (for example, PCC nurses and PJS physicians). This was assessed by the computation of t-tests of the significance of the correlations of paired traits by methods.
The second method of empirical validity was used to determine if the PCC quality scores differed significantly across hospitals. The presence of significant between-hospital differences on quality scores would provide further evidence of PCC validity. To test for between-hospital differences, the total process scale score was calculated for each of the six hospitals in the pilot test; the significance of the difference in the means was compared using analysis of variance.

Three-hospital pilot test on response rates by method of administration. The second pilot test was conducted in three additional hospitals (a tertiary medical center, a large municipal hospital, and a small rural hospital) to determine if different methods of questionnaire administration (mail versus handout) produce different response rates. A sample of 1,200 patients (400 per hospital) was selected for study. For each hospital, a consecutive series of 200 patients aged 18 years and older received the questionnaire by mail within one to two weeks after they had been discharged from the hospital (mailing). A second series of 200 patients received a copy of the questionnaire near the end of their hospital stay (handout) from nursing personnel or other hospital staff as part of the discharge process. Neither method involved efforts to recontact nonrespondents because the purpose of the pilot test was to use typical procedures used by regular hospitals. After eight weeks, the returned forms were analyzed. Data were gathered on overall response rates and on item-level response rates for fixed-response questions and open-ended comments.

Follow-up field trial of PCC system to assess response bias. Because the three-hospital pilot test showed that the response rates produced by typical methods of data collection were quite poor, we considered it critical to estimate the amount and direction of bias that would be inherent in PCC results if hospitals used mailout or handout methods to distribute the questionnaires and if they chose not to follow up nonrespondents.

Four additional hospitals participated in this field test. Each hospital had elected to use the PCC to help it obtain a steady stream of patient feedback. Our research staff explained methods for distributing the PCC and each hospital selected an approach that best suited its organization (mailing or handout). None attempted to recontact nonrespondents in order to boost response rates. In addition to using the PCC, each of the hospitals was also using the PJS. As noted earlier, the PJS system was administered to a random sample of patients in a standardized way by an independent research firm; all nonrespondents were followed with a postcard reminder and a second questionnaire. PJS respondents who did not return forms by mail were followed up by phone; respondent and nonrespondent demographic data from hospital records were compared. These results showed that although the respondents were a few years older than those in our sample, somewhat healthier, more likely to be women, and better educated than nonrespondents, the quality ratings of respondents did not differ significantly from those of nonrespondents. ${ }^{4,6}$ As a consequence, hospitalwide results from the PCC could be compared with those from the PJS, using the latter as a reasonable benchmark. The comparison was made on the basis of quality scores from patients who used the hospital during the same time period (that is, patients who were discharged during a selected quarter of the year). For instance, a hospital's quality scores produced by the PCC were compared with its quality scores produced by the PJS for the third quarter of 1990.

\section{Results}

Reliability and validity. Table 1 (p 281) provides evidence that supports the reliability and validity of the PCC rating items. Test-retest reliability of individual items ranged from 0.65 to 0.84 and averaged 0.75 . Ninety-five percent of responses to the matched items did not change or changed by only one point.

Internal-consistency reliability on the total process scale was excellent; the Cronbach's alpha coefficient was 0.89 . Furthermore, there were only small differences in average test-retest coefficients by age and education sub- 
Table 1. Six Hospital Pilot Test Results: Reliability and Validity of Patient Comment Card

\begin{tabular}{|c|c|c|c|}
\hline \multicolumn{4}{|l|}{ Reliability } \\
\hline $\begin{array}{l}\text { Test-retest } \\
\text { (matched items) }\end{array}$ & $\begin{array}{l}\text { Average correla } \\
\text { Range of correl }\end{array}$ & $\begin{array}{l}\text { tion } \\
\text { ations }\end{array}$ & $\begin{array}{l}0.75 \\
0.65-0.84\end{array}$ \\
\hline $\begin{array}{l}\text { Patient level reliability } \\
\text { Hospital level reliability }\end{array}$ & $\begin{array}{l}\text { (alpha) } \\
(\mathrm{Rtt})^{*}\end{array}$ & $\begin{array}{l}\text { Total process scale } \\
\text { Total process scale }\end{array}$ & $\begin{array}{l}0.89 \\
0.74\end{array}$ \\
\hline $\begin{array}{l}\text { Power } \\
\text { Number of patients }\end{array}$ & $\begin{array}{l}\mathrm{Rtt}=0.80 \\
\mathrm{Rtt}=0.90\end{array}$ & $\begin{array}{l}\text { Total process scale } \\
\text { Total process scale }\end{array}$ & $\begin{array}{l}N=79 \\
N=102\end{array}$ \\
\hline \multicolumn{4}{|l|}{ Validity } \\
\hline Convergent & \multicolumn{2}{|c|}{$\begin{array}{l}\text { Average convergent correlation } \\
\text { Range of correlations }\end{array}$} & $\begin{array}{l}0.72 \\
0.64-0.85\end{array}$ \\
\hline Discriminant & \multicolumn{2}{|c|}{$\begin{array}{l}\text { Average discriminant correlation } \\
\text { Range of correlations } \\
\text { Discriminant validity successes }\end{array}$} & $\begin{array}{l}0.55 \\
0.33-0.75 \\
60 \%\end{array}$ \\
\hline Variability & \multicolumn{2}{|c|}{$\begin{array}{l}\text { Average "total process" scale score } \\
\text { Average difference between hospitals } \\
\text { Range across } 6 \text { hospitals } \\
\text { Standard deviation } \\
\text { Analysis of variance: F-test } \\
\text { (p value) }\end{array}$} & $\begin{array}{l}72 \\
7.64 \\
64-82 \\
19 \\
3.12(0.01)\end{array}$ \\
\hline
\end{tabular}

Table 2. Effect of Administration Method of Patient Comment Card on Response Rate (Three Hospital Pilot Test Results)

\begin{tabular}{|llc|}
\hline Hospital Type & \multicolumn{1}{|}{$\begin{array}{l}\text { Response Rate for Two Methods of } \\
\text { Mailing (n) }\end{array}$} & $\begin{array}{c}\text { Administration } \\
\text { Handout (n) }\end{array}$ \\
\hline Small, Rural, Community Hospital & $13 \%(26 / 200)$ & $20 \%(39 / 200)$ \\
Large, Urban, County Hospital & $24 \%(47 / 200)$ & $41 \%(82 / 200)$ \\
Large, Urban, Tertiary Hospital & $16 \%(31 / 200)$ & $24 \%(48 / 200)$ \\
\hline Overall Results & $17 \%(104 / 600)$ & $28 \%(169 / 600)$ \\
\hline
\end{tabular}

groups $(0.75$ for patients under 65 years versus 0.76 for those aged 65 years or more; 0.78 for patients with a high school education or less versus 0.75 for those with more than a high school education), suggesting that reliability is just as high for older and less educated patients as for younger and more educated patients.

The hospital-level reliability estimate for the total process scale was $\operatorname{good}(\mathrm{Rtt}=0.74)$. Since the hospitallevel reliability is directly related to sample size, Table 1 also shows how large a patient sample is necessary to achieve hospital-level reliabilities of 0.80 and $0.90(\mathrm{~N}=79$ and $\mathrm{N}=102$ patients, respectively).

The convergent validity correlations measured the association between PCC and PJS matched items and scales. These correlations were all substantial, ranging from 0.64 to 0.85 and averaging 0.72 , indicating good convergence among different measures of the same trait. The discriminant validity coefficients averaged 0.55 and ranged from 0.33 to 0.75 . Results from $60 \%$ of the t-tests were statistically significant in support of the discriminant validity of the measures. These results suggest that theoretically related items (convergent) were in fact more strongly related than theoretically unrelated items within and across the two methods used.

Finally across the hospitals there was substantial variability on quality. Scores ranged from 64 to 82 on the total process scale; actual values for the six hospitals and their confidence intervals were 64 (56-71), 67 (59-75), 68 (61-75), 72 (65-80), 74 (67-81), and 82 (74-89). The average difference between hospi- tals was 7.64 points on a 0 to 100 scale. The between-hospital difference was similar in size to that observed for the PJS total process score and was statistically significant (p0.01) as measured by analysis of variance. This suggests that the PCC is sufficiently sensitive to detect between-hospital variations in quality even with small sample sizes for individual hospitals.

Response rates. Table 2 (left) summarizes the response rates observed in three hospitals for the handout versus the mailing method (no administration method used follow-up). Response rates for the mailing method ranged from $13 \%$ to $24 \%$ (average, $17 \%$ ). Response rates for the handout approach were somewhat higher, ranging from $20 \%$ to $41 \%$ (average, $28 \%$ ). Although these rates are similar to those achieved by other hospitals using similar administration methods, they are much lower than those achieved by these same hospitals with the PJS. For example, results from the most recent PJS administration using a mailing method with moderately intensive follow-up (first questionnaire followed by a reminder, postcard, and then later a second questionnaire) yielded response rates ranging from $46 \%$ to $77 \%$ (average, $61 \%$ ).

Further analyses showed that most patients who returned questionnaires answered the fixed-response questions that were relevant to them. The average rate of item nonresponse was only $3.6 \%$ for those fixed-response questions that most patients were qualified to answer, such as admissions, nurses, doctors, and so on. Items such as physical therapy and emergency department showed high "not applicable" rates (for example, $44 \%$ and $35 \%$ of patients indicated "no contact" for physical therapy and emergency room).

Many patients made comments. The frequency of comments ranged from $4 \%$ (privacy) to $41 \%$ (good experiences) on topics for which comments were requested. The five topics receiving most frequent comments were good experiences $(41 \%)$, bad experiences $(33 \%)$, nurses $(18 \%)$, food $(16 \%)$, and admissions (14\%). Women and younger patients tended to write comments more frequently than men and 
Table 3. Four Hospital Field Trial Results: Response Rates and Demographics

\begin{tabular}{|c|c|c|c|c|c|}
\hline \multirow[b]{2}{*}{ Hospital Type } & \multicolumn{2}{|c|}{ Response Rates } & \multicolumn{2}{|c|}{ Mean Age } & \multirow[b]{2}{*}{ PJS-O } \\
\hline & PCC (n) & PJS (n) & PCC & PJS-R & \\
\hline Medium, Urban, Community Hospital & $15 \%$ & $59 \%$ & 61 & 54 & 53 \\
\hline Small, Rural, Community Hospital & $17 \%$ & $50 \%$ & 56 & 52 & 51 \\
\hline Small, Rural, Community Hospital & $25 \%$ & $55 \%$ & 61 & 56 & 54 \\
\hline Large, Urban, Tertiary Hospital & $27 \%$ & $57 \%$ & 46 & 43 & 40 \\
\hline Overall Results & $21 \%$ & $55 \%$ & 56 & 51 & 50 \\
\hline \multicolumn{6}{|c|}{$\begin{array}{l}\text { PJS-R, mean age for PJS respondents (R) } \\
\text { PJS-O, mean age for PJS patients in the original }(O) \text { sample (that is, respondents and nonrespondents) } \\
\text { PJS-R, percentage of female PJS respondents (R) } \\
\text { PJS-O, percentage of female PJS patients in the original sample (that is, respondents and nonrespondents) }\end{array}$} \\
\hline
\end{tabular}

older patients.

Response rates and bias. Table 3 (above) shows response rates achieved under normal conditions (that is, hospitals that decided to use the PCC to obtain a steady stream of feedback) at four hospitals and compares characteristics of PCC respondents with those of PJS respondents. In the field test, response rates for the PCC averaged $21 \%$ (range, $15 \%$ to $27 \%$ ); rates for the PJS were more than twice as high (average, $55 \%$; range, $50 \%$ to $59 \%$ ). Compared with the PJS patients, PCC respondents tended to be several years older (average, 56 versus 51 years) and were less likely to be female ( $53 \%$ versus $58 \%$ ).

Figure 1 (p 283) compares the percentage of PCC respondents who rated the hospital "excellent" on each of nine items with the percentage of PJS respondents who rated the hospital excellent on the comparable multi-item measures. (The percentage excellent was used because patient ratings are skewed favorably and to emphasize the magnitude of improvement possible). For eight of the nine indicators, the PCC respondents rated quality more favorably; food, which is the exception, was rated "excellent" by equal percentages of respondents. For example, $57 \%$ of PCC respondents versus $35 \%$ of PJS respondents rated nursing excellent; $62 \%$ of PCC versus $41 \%$ of PJS respondents rated doctors excellent. The proportion of PCC patients rating nurses and physicians excellent was $63 \%$ and $51 \%$ greater, respectively, than the proportion of PJS patients making that rating.

Other analyses on bias were per- formed. The first, using all the PCC items and comparing the mean scores for PCC and paired PJS indicators, revealed findings similar to those shown in Figure 1. In all analyses, the PCC respondents rated quality more favorably in all four hospitals. These differences were statistically significant (p 0.01, t-tests) on all except three quality indicators - food, physical therapy, and housekeeping. The second analysis was performed to determine the extent of bias. Table 4 (p 283) shows the mean PCC and PJS quality indicator scores used in Figure 1 for each of the four hospitals. For each indicator in all four hospitals, the mean score for the PCC exceeds that for the PJS. (Table 4 shows the PCC item means for each hospital along with the comparable PJS item or scale means for relevant quality attributes. All items/ scales have been scored to range from 0 to 100 with higher scores indicating better quality.)

The third analysis was performed on the data for the six-hospital test-retest study to determine if the difference in quality scores (that is, PCC-generating higher ratings) is most related to response bias or instrument bias. Table 5 (p 283) shows the results of this analysis, which compares the mean scores for the PJS and PCC items with identical wording for the same sample of patients. Results show that the PCC produced slightly lower scores than the PJS on four items (food, privacy, family, and quality) and higher ratings on two questions (would recommend, would return). Since the PCC ratings among patients who used both forms were not found to be consistently higher or lower than the PJS ratings, these results suggest response bias rather than instrument bias.

Patient comments. Eighty patients from two hospitals made written comments, which were most frequently related to good and bad experiences. Analysis of comments showed how this system can capture "voice of the customer" feedback.

Fifty-six of the comments were complimentary (for example, "good," "super," "none better"); $14 \%$ were neutral or ambiguous (for example, regarding admissions: "came in by ambulance"), and $30 \%$ were complaints (for example, "upon entry, the room was not clean"). The most useful comments for quality improvement came from the bad experiences section (for example, "before I could talk, the nurse monitor would hang up on me when I buzzed for help"; "the mammograms were unnecessarily rough - far too much pressure and [too] many plates"). The less favorable the patient's ratings of hospital quality, the more likelihood that the patient had registered a complaint.

These results show that the $\mathrm{PCC}$ can be used to capture qualitative feedback directly from patients.

\section{Discussion}

The PCC represents an attempt to design and test a patient feedback system to offer all patients a chance to comment on the care they received and thereby gather qualitative information and provide timely quantitative measures of quality based on patient evaluations of hospital services.

Comment-generating capacity. The success of the PCC in eliciting write-in comments suggests that these comments can be used to

- document how patients judge the care they receive;

- identify what disappoints and delights them;

- spot problems experienced by individual patients;

- promote better understanding about what patients need and expect; and

- identify high-priority areas for quality improvement (if comments are aggregated and analyzed for content).

To help hospitals use PCC results, 


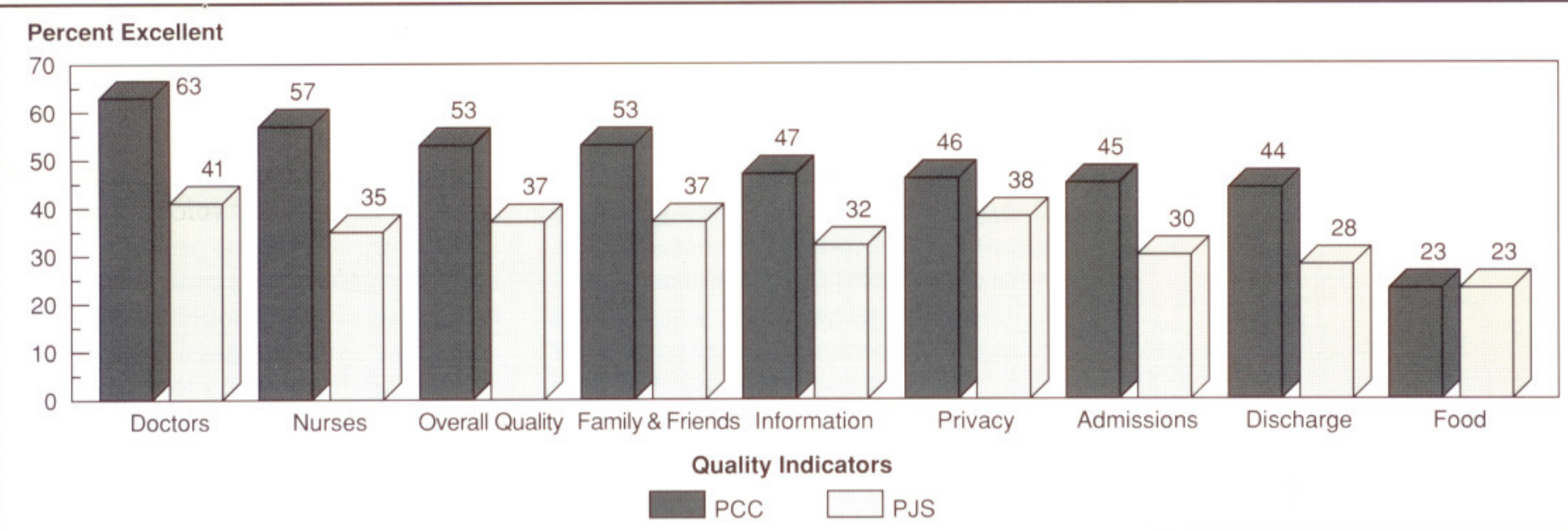

Figure 1. These results show the percentage of excellent hospital ratings by Patient Comment Card (PCC) respondence compared to those of Patient Judgement System (PJS) respondences.

\section{Table 4. Comparison of PCC and PJS Means Across Hospitals*} (Four Hospital Study Results)

\begin{tabular}{|c|c|c|c|c|c|c|c|c|}
\hline & \multicolumn{2}{|c|}{$\begin{array}{c}\text { Medium, } \\
\text { Urban, } \\
\text { Community }\end{array}$} & \multicolumn{2}{|c|}{$\begin{array}{c}\text { Small, } \\
\text { Rural, } \\
\text { Community }\end{array}$} & \multicolumn{2}{|c|}{$\begin{array}{c}\text { Small, } \\
\text { Rural, } \\
\text { Community }\end{array}$} & \multicolumn{2}{|c|}{$\begin{array}{l}\text { Large, } \\
\text { Urban, } \\
\text { Tertiary }\end{array}$} \\
\hline & PCC & PJS & PCC & PJS & PCC & PJS & PCC & PJS \\
\hline Doctors & 89 & 82 & 81 & 74 & 90 & 80 & 89 & 75 \\
\hline Nurses & 84 & 74 & 78 & 70 & 87 & 76 & 86 & 72 \\
\hline Overall Quality & 82 & 76 & NA & NA & 85 & 77 & 82 & 75 \\
\hline Family/Friends & 84 & 76 & NA & NA & 86 & 78 & 84 & 72 \\
\hline Information & 81 & 73 & 75 & 70 & 84 & 73 & 83 & 73 \\
\hline Privacy & 82 & 80 & NA & NA & 85 & 77. & 76 & 72 \\
\hline Admissions & 82 & 70 & 79 & 68 & 82 & 74 & 79 & 72 \\
\hline Discharge & 81 & 74 & 74 & 69 & 83 & 74 & 78 & 67 \\
\hline Food & 59 & 58 & 72 & 66 & 64 & 62 & 57 & 55 \\
\hline
\end{tabular}

NA, data not available because the PCC version in use by this hospital did not include these items.

Table 5. Comparison of Matched Item Responses for PCC and PJS Respondents

\begin{tabular}{|llcll|}
\hline Construct & Source & Mean & SD & $\mathbf{N}^{*}$ \\
\hline Food & PCC & 59 & 30 & 152 \\
& PJS & 62 & 33 & 152 \\
Privacy & PCC & 72 & 28 & 153 \\
& PJS & 75 & 27 & 144 \\
& PCC & 75 & 24 & 148 \\
Quality & PJS & 77 & 25 & 153 \\
& PCC & 74 & 25 & 157 \\
Recommend & PJS & 76 & 17 & 155 \\
\multirow{4}{*}{ Return } & PCC & 65 & 19 & 146 \\
& PJS & 64 & 17 & 151 \\
& PCC & 24 & 146 \\
PJS, subset of patients who also completed the PCC & 57 & & 150 \\
\hline
\end{tabular}

the University of Wisconsin has worked with the National Demonstration Project for Quality Improvement in Health Care, Brookline, Massachusetts, and the Hospital Corporation of America (HCA) to create a computer program by which to enter, analyze, and manage PCC comments and quality indicators.*

Also, HCA is working with a computer manufacturer on a new system for automating data entry and data analysis of the rating items.

PCC's measurement properties: lessons learned. The first pilot test showed that the quality indicators are reliable and valid. The second pilot test showed that respondents answered most of the questions they were qualified to answer

\footnotetext{
${ }^{*}$ Users select the services (for example, nursing, admissions, and so on) they would like to examine, the type of comment (compliments, complaints, or both), the service area(s) covered (for example, pediatric unit), and the time period. The computer can display Pareto charts of the number of comments or average quality score for each service area. It can also display a control chart showing changes in comments and quality scores over time. Users can review the actual comments related to a particular service area or exam. ine the complete contents of any patient's PCC. This program is part of the Quality Improvement Support System (QISS) serving 36 hospitals and other health care organizations to help monitor quality improvement projects; share ideas via electronic mail, bulletin boards, and discussion groups; and use expert systems to examine difficult, qualityrelated decisions and conflicts.
} 
The Patient Comment

Card: A System to Gather Customer Feedback

and that they often added comments. However, this test also produced a warning signal: response rates for both mail and hand distribution without follow-up were poor (range, $15 \%$ to $30 \%$ ).

This finding prompts a major concern. If hospitals distribute the PCC without follow-up as is commonly done, they will probably obtain poor response rates, which, in turn, could produce biased and misleading quality measures. To assess this possiblity, the PCC was field tested in a number of hospitals simultaneously. The results confirmed our fears. When compared with the PJS - which, as stated, is administered by a professional survey research firm, involves follow-up of nonrespondents, has been extensively validated, and typically produces response rates of $60 \%$ or higher - the PCC consistently generated more favorable ratings. PCC scores, in most instances, appear to produce accurate "relative" results but incorrect "absolute" values. The observed bias is unlikely to be caused by the instrument itself since the quantitative results for the subset of patients who completed the two different forms (PCC and PJS) - which shared some items - were similar. The bias is more likely to be due to the comparatively low response rate-a problem that could be corrected with aggressive nonrespondent follow-up. We speculate that the measurement bias would decrease with better follow-up and frequently higher response rates.

Methodologic and conceptual comments. This study brings up some interesting issues. First, it would be interesting and useful to directly assess the response rate for the $\mathrm{PCC}$ vis-a-vis that of the PJS under identical followup conditions. All things being equal, we might assume that the response rate would be higher for the PCC because it is shorter; conventional wisdom suggests that the briefer the form the higher the response rate. Factors other than questionnaire length, however, contribute in large and small ways to the response rate. Variables such as degree of personalization, research sponsorship, confidentiality, appearance of the questionnaire forms, nature of the questionnaire and use of data, presence of tangible incentives, and even postage type used can enhance or erode response rates.

Second, the signpost and descriptor format of the PCC has advantages and disadvantages. On the one hand, this format makes it easy for the patient to make quality ratings; the signpost signals areas of interest and then uses the descriptors to operationalize particular facts of the construct being rated. In effect, an operational definition is contained in the item stem. However, the signaling effected by the signpost and the blocking of questions together may "create" factors regardless of the substantive meaning of various questions. If this occurs, it would produce an inflated internal consistency statistic (that is, Cronback's alpha) for the total process scale.

Third, the PCC groups certain quality attributes differently than do some earlier patient satisfaction questionnaires. For example, questionnaires developed by Ware et al and Hulka et al were designed to enable patients to rate care delivered by providers according to interpersonal versus technical quality of care. ${ }^{11,12}$ Many PCC items, in contrast, combine aspects of the quality of care, including interpersonal and technical aspects, into a single question (for example, nurses' skill, caring and concern shown by nurses, attention to condition, information provided, response to calls).

Use and abuse of patient feedback. Health care organizations need to determine their goals in gathering patient feedback. Is it to gain general information on patients' views of care? Is it to offer every patient the chance to have his or her voice heard? Is it to identify patients who are dissatisfied with their care and to correct the prob- lem? If these are the goals of gathering patient feedback, then a brief questionnaire and an inexpensive data collection system may suffice. Is the goal to measure quality with reliable and valid patient-based indicators that leaders can use to allocate resources for improving quality and to precisely monitor quality trends? If so, at least a follow-up system to promote higher response rates - and probably a more comprehensive and sophisticated measurement system - should be considered. Such a system would be more expensive to implement than that of a simple questionnaire.

Most hospitals could benefit from using cost-efficient, simple systems like the PCC to obtain patient comments. Not all hospitals would benefit from using a more costly and accurate system for measuring patient satisfaction because measurements always produce "results." These results are just as likely to be abused or misinterpreted as they are to be used wisely, especially in organizations in which numbers are used as clubs to beat people into doing better work; in such organizations the full set of process variables responsible for causing a result are unknown and not even under suspicion. For example, a hosptial administrator might blame the director of the admissions department for bad admission system scores, failing to realize that patients' ratings actually reflect events that take place not just in the admissions department but all over the hospital.

This scenario raises critical questions: How can hospital leaders and other providers avoid misusing quality measures? How can they promote the wise use of quality measures for real learning and to assist quality improvement? Organizations should consider the following points for making wise use of patient feedback:

- Effective use of quality measures starts with top leaders who understand who their customers are, what their customers need, and how processes need to work to efficiently match services with needs;

- There are few more powerful motivators for change than patient feedback, which can teach providers about customer needs and expectations and 
about how an entire hospital can be seen as one integrated system;

- Patient feedback can be used to encourage thinking and deeper analysis about processes, outcomes, and people in the health care system; and

- Comparing one department to another or one system to another can be useful if it helps shed light on ways procesess must work to produce better results. However, simplistic comparisons of outcomes across different departments or systems can cause harm if they are used to reward or punish; some departments or systems will always perform above average and some below average. The point is to find better ways to perform tasks, not to grade departments or systems on the basis of past performance.

These points touch on a few aspects of a comprehensive theory for quality management, which has been pioneered by teachers such as Deming and Juran and has been applied in organizations throughout the world. ${ }^{7.12-14}$

\section{Conclusion}

The PCC is useful for gathering qualitative feedback in the form of written comments from discharged patients. Furthermore, it has the potential to produce valid and reliable measures of quality. However, if the PCC, like most hospital patient satisfaction measures, is used with no follow-up of nonrespondents, like most hospital patient satisfaction measures, then it is likely to produce upwardly biased and misleading scores. This suggests that unless the PCC is used as part of a carefully designed and well managed system to sample, distribute, and collect completed forms from a representative group of patients, then the scores should not be used as absolute measures of quality.*

*Both the PCC and PJS are copyrighted;
samples are available free by request from
Eugene Nelson. The original PJHQ form in its entirety has been published (see reference 4).

\section{References}

1. Nelson EC, et al: Medical and Health Guide for People Over Fifty: A Program for Managing Your Health. Glenview, IL: Scott, Foresman and Company, 1986.

2. Iglehart JK: Completion and the pursuit of quality: A conversation with Walter McClure. Health Aff 7:79-90, 1988.

3. Berwick DM: Sounding Board: Continuous improvement as an ideal in health care. New Engl J Med 320:53-56, 1989.

4. Meterko M, Nelson EC, Rubin HR (eds): Patient judgments of hospital quality: Report of a pilot study. Med Care 28:10-14, 1990 (supplement).

5. Gillem TR, Nelson EC: Hospital quality trends. In Spechler J (ed): When Amer ica Does It Right. Norcross, GA: Industrial Engineering and Management Press, 1988.

6. Nelson EC, et al: The patient judgment system: Reliability and validity. $Q R B$ 15:185-191, 1989.

7. Walton M: Hospital Corporation of America (Chapter 3). In Deming WE, Management at Work. New York: GP Putnam's Sons, 1990.

8. Batalden PB, Nelson EC: Hospital quality: Patient, physician and employee judgments. Quality Assurance in Health Care 3:7-17, 1990.

9. Hays RD, et al: Hospital quality trends: A short-form patient-based measure. Med Care 29:661-668, 1991

10. Ware JE, Hays RD: Methods for meas uring patient satisfaction with specific medical encounters. Med Care 26:393-402, 1988.

11. Hays RD, et al: User's Guide for the Multitrait Analysis Program. Santa Monica, CA: The Rand Corporation, 1988.

12. Hulka BS, et al: Scale for the measurement of attitudes toward physicians and primary medical care. Med Care 8:429-435, 1970.

13. Ware JE: Effects of acquiescent response set on patient satisfaction ratings. Med Care 16:327-336, 1978.

14. Deming WE: Out of the Crisis. Cambridge, MA: Massachusetts Institute of Technology Center for Advanced Engineering Study, 1986.

15. Juran JM: Juran's Quality Control Handbook. New York: McGraw-Hill, 1988.
16. Garvin DA: Managing Quality: The Strategic and Competitive Edge. New York: The Free Press, 1988.

17. Gitlow HS, Shelly J: The Deming Guide to Quality and Competitive Position. Englewood Cliffs, NJ: Prentice Hall, Inc, 1987.

18. Ishikawa K: What Is Total Quality Control? Englewood Cliffs, NJ: Prentice Hall, Inc, 1985.

19. Juran JM: Juran on Planning for Quality. New York: The Free Press, 1988.

20. Scholtes PR: The Team Handbook: How to Improve Quality with Teams. Madison, WI: Joiner Associates Inc, 1988.

21. Shores AR: Survival of the Fittest. Milwaukee: American Society for Quality Control Quality Press, 1988.

22. Walton M: The Deming Management Method. New York: Dodd, Mead Company, 1986.

23. Senge PM: The Fifth Discipline. New York: Doubleday, 1990.

24. Berwick DM, Godfrey AB, Roessner J: Curing Health Care: New Strategies for Quality Improvement. San Francisco: Jossey-Bass Inc, 1990.

25. Nelson EC, et al: Gaining customer knowledge: Obtaining and using customer judgments for hospitalwide quality improvement. Topics in Health Record Management 11(3) 13-26, 1991.

26. Nelson EC: Using outcome measures to improve care delivered by physicians and hospitals. In Heithoff K, Lohr K (eds): Effectiveness and Outcomes in Health Care: Institute of Medicine 1990 Proceedings. Washington, DC: National Academy Press, 1990.

27. Donabedian A: The quality of careHow can it be assessed? JAMA 260:17431748, 1988.

28. United States Congress, Office of Technology Assessment: The Quality of Medical Care: Information for Consumers. OTA-H-385. Washington, DC: U.S. Government Printing Office, June 1988.

29. Davies AR, Ware JE, Jr: Involving consumers in quality of care assessment. Health Aff 7:33-48, 1988. 


\section{HOSPITAL REPORT CARD}

How did you feel about the quality of these services?

Check the correct face to show if they were: excellent, very good, good, fair, poor or you had no contest with the service. Give us your comments and suggestions

Admissions. . . information you were given about what to expect. ease of getting admitted, amount of time it took, attention to your

$$
\begin{aligned}
& \text { (:) } \\
& \begin{array}{c}
\text { excellent, very good, } \\
\text { COMMENTS: }
\end{array}
\end{aligned}
$$

Your Nurses. . . skill, caring \& concern shown by nurses, atten tion to your condition, information provided. response to your cals

(1)
$\begin{gathered}\text { excellent, very good, } \\ \text { COMMENTS: }\end{gathered}$

Your Doctors. . . skill. caring \& concern shown by dectors attention to your condation. information provided, ease of seeiny doctors, teamwork among doctors

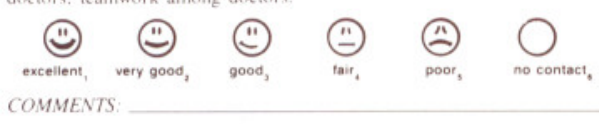

Quality of Food... how good it tasted, serving temperature.

(1)
excellent,
COMMENTS:

Privacy. ...arrangements for your privacy

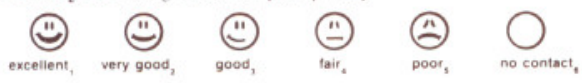

COMMENTS:

Information... . willingness of hospital staff to answer questions keep family \& friends informed about your condition.

(1)
excellent, very good,
COMMENTS:

Family and Friends. . . treatment of family and other visitors by staff, adequacy of visiting hours, facilities for visitors-

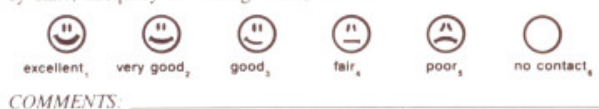

Discharge... .time it took, information about what to do after leaving the hospital, coordination of care after discharge.
(:)
(:) :)
(-):
(2) $\bigcirc$

COMMENTS

Hospital Quality... How would you rate the overall quality of excellent, very good,
COMMENTS:
How would you rate both the quality of the service and the way staff treated you? Were they excellen, very good, good, fair, poor, or you had no contact with the service? Check the correct box

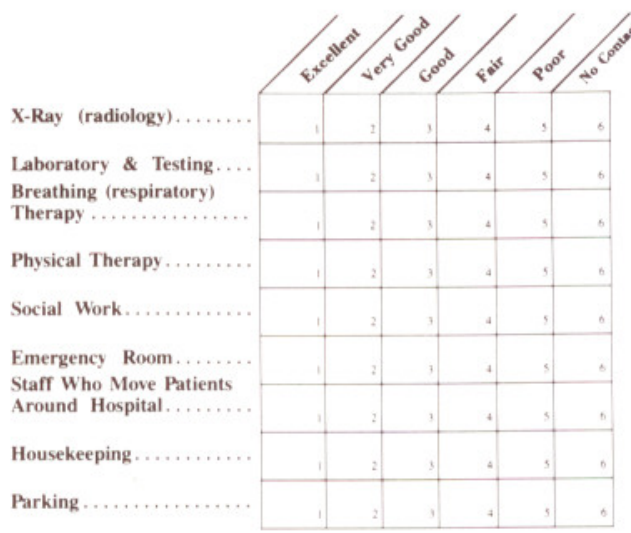

Good Experiences: Did anything good happen during your stay in the hospital that surprised you? If so, please tell us what it was

Bad Experiences: Did anything bad happen during your stay in the hospital that surprised you? If so, please tell us what it was

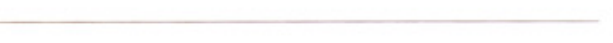

\begin{tabular}{c}
\hline Return... \\
Would you return to this hospital if you needed \\
to be hospitalized again? \\
$\square$ Definitely Yes, $\square$ Definitely Not N $_{4}$ \\
$\square$ Probably Yes \\
$\square$ Probably Not \\
COMMENTS:
\end{tabular}

\section{ABOUT THE PATIENT}

Where did you stay in the hospital? In a section of the hospital for. . (check all that apply)

$\begin{array}{ll}\text { Adult Medical } & \square \text { Rehabilitation } \\ \text { Adult Surgical } & \square \text { Childbirth/maternity } \\ \text { Heart/coronary care } & \square \text { Children/pediatrics } \\ \text { Intensive/critical care } & \square \text { Don't know or Other }\end{array}$

What was the number of your room?

In what year were you (the patient) born?

Are you (the patient) male or female? $\square$ Female $\square$ Male

On what date were you (will you be) discharged from the hospital?

Name (optional)

Address

City State Zip

Telephone 